\title{
Opioid-based micro and nanoparticulate formulations: alternative approach on pain management
}

\section{André São Pedro, Renan Fernandes, Cristiane Flora Villarreal, Rosana Fialho \& Elaine Cabral Albuquerque}

To cite this article: André São Pedro, Renan Fernandes, Cristiane Flora Villarreal, Rosana Fialho \& Elaine Cabral Albuquerque (2016): Opioid-based micro and nanoparticulate formulations: alternative approach on pain management, Journal of Microencapsulation, DOI: 10.3109/02652048.2015.1134687

To link to this article: http://dx.doi.org/10.3109/02652048.2015.1134687

\section{Published online: 20 Jan 2016.}

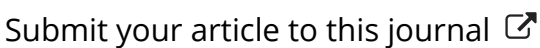

Џll Article views: 4

Q View related articles $\sqsubset$

View Crossmark data 5 


\title{
Opioid-based micro and nanoparticulate formulations: alternative approach on pain management
}

\author{
André São Pedro ${ }^{a}$, Renan Fernandes ${ }^{b}$, Cristiane Flora Villarreal $^{b, c}$, Rosana Fialho ${ }^{a}$ and Elaine Cabral Albuquerque ${ }^{a}$

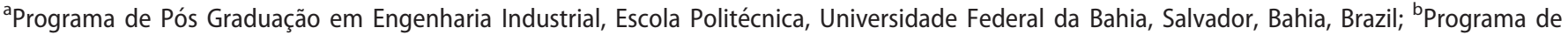 \\ Pós-Graduação em Farmácia, Faculdade de Farmácia, Universidade Federal da Bahia, Salvador, Bahia, Brazil; 'Laboratório de Imunofarmacologia e \\ Engenharia Tecidual, Centro de Pesquisas Gonçalo Muniz - Fiocruz, Salvador, Bahia, Fiocruz, Brazil
}

\begin{abstract}
Context Opioids have been used as the reference treatment on chronic pain. However, they are related to serious adverse effects which affect the patient compliance to treatment, as well as, his quality of life. Particulate formulations have been investigated as an alternative to improve opioid efficacy and safety. Objective Summarise the available studies concerning micro and nanoencapsulated opioid formulations discussing their biopharmaceutical characteristics, such as composition, size, in vitro release, pharmacokinetic and antinociceptive profile. Methods Papers available in 1995-2015 at Medline, Science Direct and Web of Science databases were collected and assessed. Searches were performed using varied combinations of the keywords of this work. Results Opioid-loaded particles showed prolonged drug release with maintenance of serum therapeutic concentrations and extended analgesia when compared with the free drugs. The side effects incidences were reduced or maintained the same. Conclusion Particulate formulations can significantly increase both potency and safety profiles of opioids.
\end{abstract}

\section{ARTICLE HISTORY}

Received 24 April 2015

Revised 21 October 2015 Accepted 9 November 2015 Published online 19 January 2016

\section{KEYWORDS}

Opioids; liposomes; polymer particles; solid lipid nanoparticles; nanostructured lipid carriers

\section{Definitions and background}

The term opioid was originally stated for defining natural alkaloids extracted from opium, and afterwards extended to their synthetic and semisynthetic derivatives (Bourland, 2011). Currently, there has been a great confusion between the terms opioids and opiates in literature. In this context, Reisfield et al. (2007) have stated the term opiate specifically to substances extracted from poppy seed latex, such as morphine and codeine. The term opioid includes very different chemical substances with some degree of agonist activity on opioid receptors through the nervous system. Thus, opioids include some opiates, semi-synthetic, synthetic derivatives, as well as peptides. Opium is composed of dried latex obtained from the pods of Papaver somniferum, commonly known as poppy, which has been cultivated since 3400 BC in ancient Mesopotamia (Trescot et al., 2008b). The use of opium for pain relief is described in ancient Egyptian papyri dated from 1552 BC (Breasted, 2001). Through the years, a plenty of clinical studies evidenced the remarkable analgesic activity of opioid molecules which made them being taken as the gold treatment for chronic pain and severe acute pain (WHO, 2007). Table 1 lists some opioid molecules distributed according to their origin, including opioid peptides.

Despite the confusion in defining chronic pain, the definition provided by the International Association for the Study of Pain (IASP) is considered as an international standard (Doth et al., 2010; VanDenKerkhof et al., 2014). This concept remains the same since 1986 and establishes chronic pain as the pain that persists beyond normal tissue healing time, i.e. 3 months or more (Merskey and Bogduk, 1994).
Previous data has shown chronic pain affecting around $20 \%$ of the European population and is more common in women and elderly (Van Hecke et al., 2013). In Germany, a study reported 39.2\% of prevalence of chronic pain (Häuser et al., 2013). Johannes et al. (2010) showed that the prevalence in the US reaches about $30.7 \%$. A Canadian study conducted by Schopflocher et al. (2011) reported $18.9 \%$ of population suffering from chronic pain. In Hong Kong, this value reached 34\% (Fielding and Wong, 2012), while Japan demonstrated $17.5 \%$ (Sakakibara et al., 2013).

Chronic pain is also marked by its impact upon public economy. Only in the US, the total costs ranged from $\$ 560$ to $\$ 635$ billion in 2010. This value exceeds the annual costs of heart disease $(\$ 309$ billion), cancer ( $\$ 243$ billion) and diabetes ( $\$ 188$ billion) (Gaskin and Richard, 2012). Europe has an estimated cost of 200 billion Euros a year with chronic pain (Tracey and Bushnell, 2009). These expenses are mainly composed of total health care costs attributable to pain and annual costs of pain associated to decrease on work productivity (Gaskin and Richard, 2012).

The use of opioids as therapy for chronic pain has increased over the past few decades. However, there has been a concern to its analgesic efficacy, since it usually decreases through the course of treatment, despite increasing doses (Ballantyne and Shin, 2008). This pattern is related to development of tolerance to opioid therapy (Dumas and Pollack, 2008). This tolerance is evidenced during longterm treatment with opioids in which neuroadaptation takes places altering the normal function of nervous system homeostasis, desensitising opioid receptors and altering nociceptive signalling (Ballantyne and Shin, 2008; Allouche et al., 2014). This is a result of concomitant complex mechanisms, such as metabolic changes,

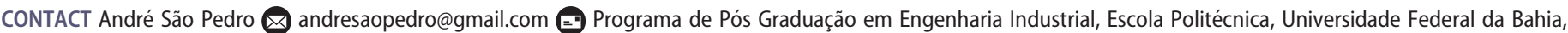
Salvador, Bahia, Brazil 
Table 1. Opioids classified according to their origin.

\begin{tabular}{llll}
\hline Natural & Semisynthetic & Synthetic & Peptides \\
\hline Morphine & Diamorphine & Butorphanol & DAMGO $^{1}$ \\
Codeine & Dihydrocodeine & Fentanyl & DALDA $^{2}$ \\
Papaverine & Buprenorphine & Alfentanil & DTLET $^{3}$ \\
Thebaine & Etorphine & Sufentanil & \\
& Nalbuphine & Methadone & \\
\hline
\end{tabular}

\footnotetext{
${ }^{1}$ Synthetic peptide [D-Ala2, N-MePhe4, Gly-ol].

${ }^{2}$ Endogenous peptide [Tyr-D-Arg-Phe-Lys- $\mathrm{NH}_{2}$ ]

${ }^{3}$ Synthetic peptide [d-Thr2,Leu5,Thr6].
}

Table 2. Adverse reactions caused by the use of opioids.

\begin{tabular}{ll}
\hline Central & Peripheric \\
\hline Tolerance & Immunological changes \\
Physical dependence & Hormonal changes \\
Sedation & Hyperalgesia \\
Sleep Disorders & Constipation \\
& Urinary disorders \\
& Cardiovascular changes \\
\hline
\end{tabular}

mediated by enzyme expression modulations and alterations on transporters functions (Dumas and Pollack, 2008).

Further, as described in Table 2, a large spectrum of possible adverse reactions can be developed due to the prolonged use of opioids. The awareness of opioid tolerance and adverse reactions are closely related to a fear of physicians in prescribing opioids for pain management and also to patient non-compliance, which sadly lead to adoption of subtherapeutic schemes (Trescot et al., 2008a; Manchikanti et al., 2010).

Taking into account that several opioids, such as morphine, oxycodone and hydromorphone possess very short half-lives, they commonly require frequent administration leading to inconsistent drug levels and a higher incidence of adverse events. Therefore, the use of extended-release formulations modulate the drug absorption providing constant and more predictable therapeutic drug levels improving the safety of opioid therapy. There is also more efficient coverage of analgesic gaps, even when compared with naturally long-acting opioids, such as methadone (Holt et al., 2007; Wood et al., 2010; Ngwuluka et al., 2013).

\section{Micro and nanoparticulate formulation}

For several years, the research on development of drug formulations has been focussed on tailoring of delivery systems which are capable of delaying and sustaining the drug release post-administration (Maderuelo, 2011). These kind of formulations, commonly known as modified drug delivery systems, present several advantages when compared to conventional pharmaceutical forms. Their capability of maintaining constant drug blood levels confers to them improved efficacy, reduced toxicity, improved patient compliance and convenience (Lehner et al., 2013). In addition, delayed drug release formulations are usually designed for controlled drug release. Controlled release may be defined as a method which allows controlling time and the site of drug release at a specific rate (Zhang et al., 2013).

Among the controlled drug release systems, colloidal dispersions have been playing a prominent role on pharmaceutical research field. Colloidal dispersions are known as systems composed of particles, in which at least one of their dimensions presents a colloidal size $(1-1000 \mathrm{~nm})$, of varied nature, are dispersed in a continuous phase of a different composition. Specific physical characteristics are commonly attributed to colloids, such as light scattering, Brownian particle movement and alteration of colligative properties of solutions. Formerly, colloidal particles ranging from 10 to $1000 \mathrm{~nm}$ have been stated as nanoparticles (Huber, 2005; Olivier, 2005). More recently, only particles that possess $<100 \mathrm{~nm}$ size had been stated as nano- and those ranging from 100 to $900 \mathrm{~nm}$ have been assumed as submicron-sized particles (Fraser et al., 2008; Fang et al., 2010).

The small dimension of nanoparticles allows their facilitated passage across biomembranes, increasing significantly drug typical bioavailabilities. In addition, the large surface area of nanoparticles collaborates with the improvement of drug solubility rates into biological fluids (Fröhlich and Roblegg, 2012; Campbell and Hoare, 2014). These special characteristics confer alternative strategies for approaching complex treatments. In this context, varied nanoparticle formulations have been assessed upon clinical trials, as well as, some of them have been approved by Food and Drug Administration (FDA) for commercialisation (Lehner et al., 2013). Besides controlling the release on different sites of the body, these nanoparticle carriers can also protect drug molecules from potential thermal and photo-mediated oxidation reactions, as well as, hydrolysis and other chemical transformations during shelf life.

In this context, microparticulated systems $(>1000 \mathrm{~nm})$ also remain as a significant alternative for drug delivery, presenting some advantages when compared to nanoparticles. Microparticles preparation usually demands simpler methods, with easier scale up. The larger structure of microparticles allows loading higher amounts of drug into their matrices, demanding less concentrated doses to reach therapeutic levels during treatment. Further, their smaller surface area leads to a less susceptibility to physicochemical degradations (Kohane, 2007).

It is important to state that the main aspect that runs the choice between micro and nanoformulations is the intended application. The pharmacokinectic profile of micro and nanoparticles differ greatly as a result of significant differences on immune system uptake pathways, affinity to plasmatic proteins, absorption and accumulation rates, as well as, drug release mechanisms (Chakravarthi et al., 2010; Hardy et al., 2013).

\section{Liposomes}

Liposomes are vesicles constituted of hydrophobic phospholipid bilayers separated by aqueous compartments that cover one or multiple aqueous cores (Figure 1). Through the years, a large range of different types of liposomes have been developed with respect to lipid composition, number of bilayers, size, charge and preparation methods. Taking into account the presence of compartments with different chemical natures, it is feasible the entrapment of both hydrophilic and hydrophobic drug molecules (Lasic, 1993; New, 1990). The similarity of the lipid bilayers of liposomes with cellular membranes makes them good candidates for studying drug-cell interactions. Furthermore, it allows the delivery of the drug into an intracellular environment. This delivery can also be targeted by use of a wide range of receptor-specific ligands on liposomal membrane leading to drug release on specific tissues or cell types (Allen and Cullis, 2013). These features justify the versatility and popularity of liposomal products.

Considering all these advantages, researches have been carried out focussing on the manufacturing of liposomal opioid formulations. Table 3 reveals a number of works that evaluated the performance of opioid molecules entrapped into liposomes in different experimental models.

Since the 1990s, various works have been published describing the elongation of duration of analgesia, with no significant 


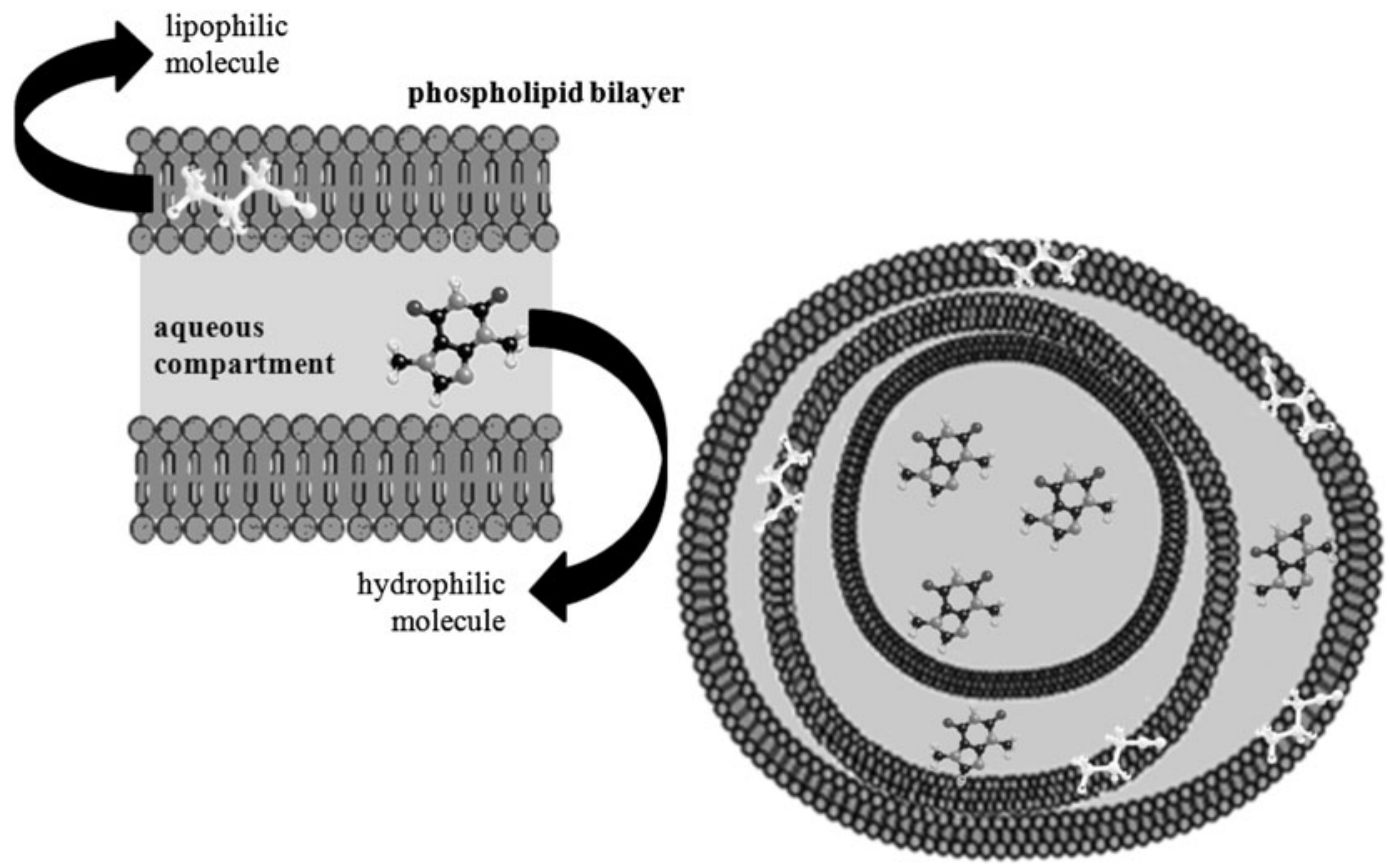

Multilamellar Liposome

Figure 1. Scheme of lipophilic and hydrophilic molecules entrapped into different compartments of a liposome.

increment or even reduction of systemic side effects of opioids encapsulated on liposomes when compared to standard formulations (Bernards et al., 1992; Grant et al., 1994; Yaksh et al., 1999). These findings highlight the liposomal carriers as suitable candidates for chronic pain treatment investigation. In a study with a neuropathic pain model in Sprague-Dawley rats, liposomal morphine and oxymorphone prevented hyperalgesia for up to 7 days after one subcutaneous dose (Smith et al., 2003). The slow drug release from liposomes could explain this result. Correlating to this hypothesis, other work performed with rhesus macaques demonstrated the persistence of oxymorphone in serum for over 2 weeks after a single subcutaneous dose of liposomal formulation, whereas the standard oxymorphone concentration decreased rapidly after injection (Krugner-Higby et al., 2009). A similar result was observed for liposomal butorphanol. The plasma free butorphanol concentration usually decays drastically $2 \mathrm{~h}$ after IV administration (Groenendaal et al., 2005; Knych et al., 2013). A sustainable release for up to $24 \mathrm{~h}$ of butorphanol on Sprague-Dawley rats bloodstream was achieved with a transdermal liposomal formulation (Lim et al., 2008).

Considering the combined degrading effects of the acidic $\mathrm{pH}$ of the stomach, bile salts and pancreatic lipases on gastrointestinal tract, the administration of liposomal suspensions by oral via is limited (Shaji and Patole, 2008). Thus, polymer coating has been taken as an alternative. Further, polymer coating is also largely used for prolonging the maintenance of liposomes in blood circulation by avoiding immune system uptake (Watanabe et al., 2012). Concerning to this, a couple of works have studied polymer-coated liposomal opioids, such as PEG for tramadol (He et al., 2010) and Eudragit ${ }^{\circledR}$ S100 for endomorphin-1 (Eskandari et al., 2013). In both works, the coating significantly improved the retard on drug release. Eudragit ${ }^{\circledR}$ S100 coating also improved the passage of liposomal endomorphin-1 across gastric cells. The polymer acted not only as a shell, but also as a permeation enhancer on gastric epithelium.

On the other hand, the coating material can facilitate the interaction with biomembranes. Hoekman et al. (2014) investigated the performance of Arg-Gly-Asp (RGD) peptide-coated liposomes entrapping fentanyl on tail-flick test after nasal administration in Sprague-Dawley rats. The liposomal fentanyl exhibited greater analgesic effect, as well as, reduced drug in the plasma around $20 \%$ which leads to less adverse reactions occurrence. It was hypothesised that, due to the integrin-binding properties of the RGD peptide, the liposomes most likely bound to the epithelium after aerosol deposition on nasal tract, creating a local depot effect of fentanyl on nasal and olfactory epithelium.

Taking into account that several opioids, mainly those morphinelike, are typically hydrophilic, they are usually entrapped into multilamellar liposomes in which the varied number of aqueous cores and higher diameter enable higher entrapment efficiency when compared with the unilamellar type. Membrane interaction studies demonstrated that morphine, codeine and other synthetic derivatives were located into aqueous core of DPPC liposomes with large interaction with phosphate groups into inner membrane surface preventing the phospholipid mobility into the membrane making the liposomes rigid (Budai et al., 2003).

Considering the modified release of the encapsulated opioids, dose adjustments are mandatory. A single dose of a liposomal formulation is higher than a single dose of an immediate release drug, however the cumulative dose over the extended time period is similar. Generally, a liposomal opioid is administered at 10 times the parenteral dose for the free drug (Krugner-Higby et al., 2009). Unfortunately, there is still a lack of studies on liposomal opioids, which compromises the comprehensive analysis of the different observed phenomena.

On the other hand, some disadvantages of this carrier must be taken into consideration. Liposomal preparations have a relevant tendency to aggregate leading to drug release, with subsequent degradation and increase of toxic potential (Risselada, 2009). The usual presence of organic solvent residues has been also a concern (Gregoriadis, 2007). Besides, there is difficult in running sterilisation processes of liposomal particles without affecting their integrity (Mehnert and Mader, 2001; Mozafari, 2005). 


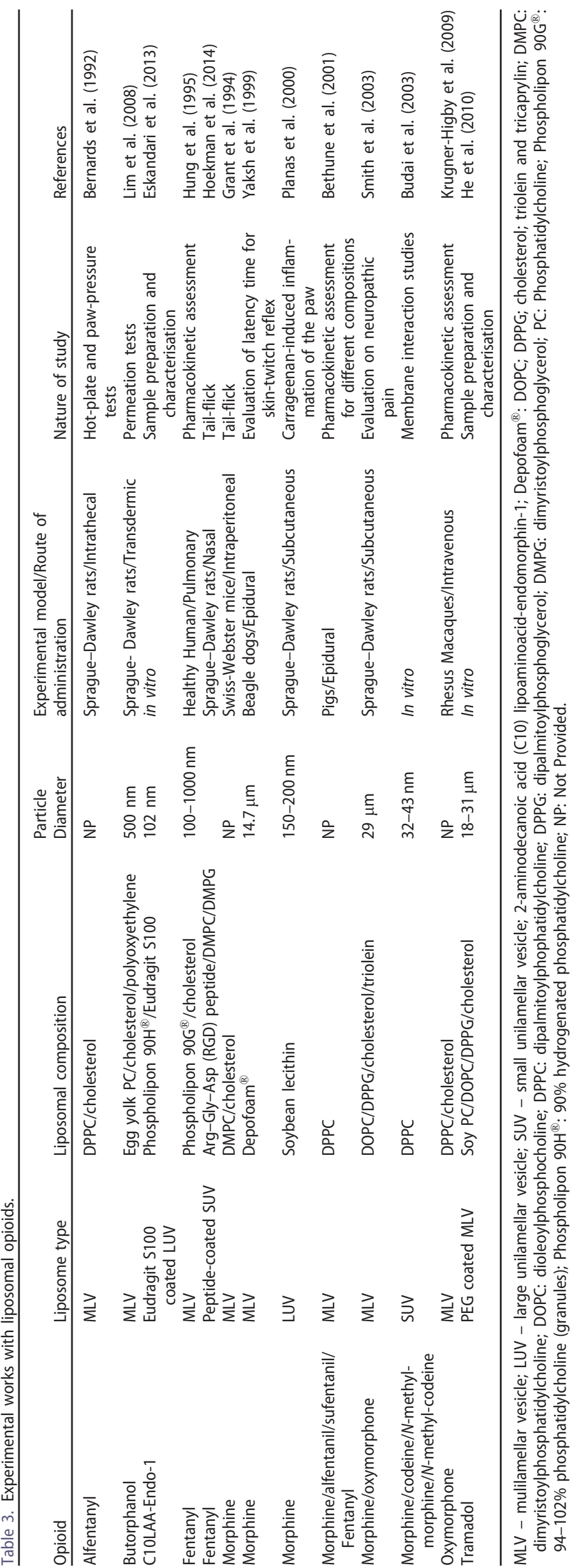

\section{Marketed liposomal opioids}

On 18 May 2004, the extended-release epidural morphine (EREM) was first approved by the FDA under the trade name Depodur ${ }^{\circledR}$. This formulation was designed for management of post-operative pain in many types of surgery, including deep abdominal surgeries, hip and knee replacements, hysterectomies, caesarean sections and other surgical procedures involving pain that can be blocked by epidural administration (Mantripragada, 2003). Depodur ${ }^{\circledR}$ is composed by the opiate morphine sulphate entrapped into micrometric multivesicular liposomes named Depofoam ${ }^{\circledR}$ developed by Pacira Pharmaceuticals Inc. (San Diego, CA), previously known as SkiePharma Pharmaceuticals Inc. (Cambridge, MA). Depofoam ${ }^{\circledR}$ has a singular structure that includes hundreds of enclosed bilayers which form several aqueous pockets where morphine salt is retained, as depicted in Figure 2 (Mantripragada, 2003; Pasero and McCaffery, 2005; Nagle and Gerancher, 2007).

After a Depodur ${ }^{\mathbb{B}}$ single injection into the epidural space, a prolonged and sustained release of morphine is provided for up to $48 \mathrm{~h}$ by erosion or reorganisation of the lipid membranes. This procedure offers various advantages, such as elimination of multiple injections and an indwelling epidural catheter, continuous pain relief, improved safety, greater convenience for patient and physician and faster patient recovery from surgery (Mantripragada, 2003; Pasero and McCaffery, 2005). However, in some clinical conditions, the EREM can demand supplementation on pain pharmacotherapy and present an analgesic profile comparable to that conventional approach (Gambling et al., 2005; Vanterpool et al., 2010; Sugar et al., 2011). Up to date, Depodur ${ }^{\circledR}$ is the only liposomal opioid commercially available.

\section{Polymer particles}

Another carrier system with large application on drug delivery is composed by polymeric particles. The polymeric carriers are able to create amorphous solid dispersions in which the drug can be distributed in the molecular state as a solid solution or solid suspension. This amorphous condition facilitates the solubilisation of the drug into biological fluids, enhancing the biodistribution of hydrophilic as well as poorly water-soluble drugs (Buttini et al., 2012). Furthermore, the availability of a wide range of synthetic, semi-synthetic and natural polymers offers a plethora of possibilities for drug delivery system design, in which is highly important to possess a non-toxic, biocompatible and biodegradable profile (Anderson and Shive, 2012).

Two main types of polymer particles have been used on drug formulation preparations: spheres and capsules. Spheres have a massive matrix in which the entrapped molecule can be distributed in small aggregates, or molecularly distributed, i.e. homogenously dispersed, or either on the sphere surface. Capsules are core-shell systems in which a core of different composition from outer layer is present (Pinto Reis et al., 2006). Figure 3 depicts spheres and capsules with different schemes of distribution of the drug molecules

Polymer particles have important advantages when compared with liposomes. Among them, their superior stability due to their solid nature with low tendency to aggregate confers to polymeric particulate products a larger shelf life. In addition, the relatively easiness with which particle size and surface characteristics of these particles can be modified allows their application for both passive and active drug targeting after parenteral administration (Gelperina, 2005; Mohanraj and Chen, 2006).

Other interesting features make this kind of particulate system the first choice for a series of uses. These includes the ability of 


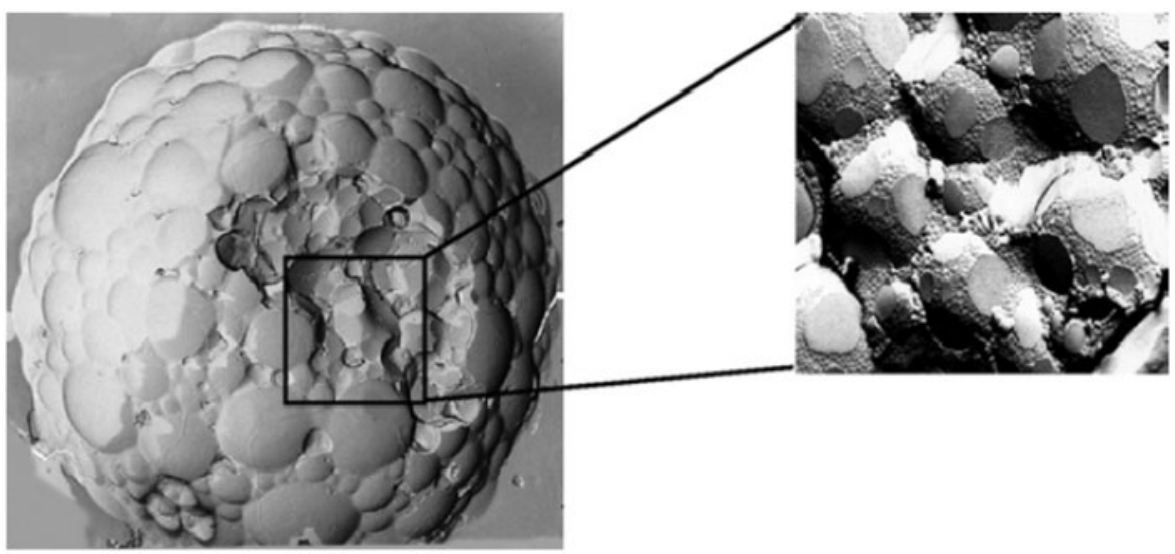

Figure 2. Electron micrograph of freeze-fracture replicas of the multi-vesicular liposome particle (DepoFoam ${ }^{\circledR}$ ) carrying morphine sulphate (Nagle and Gerancher, 2007).

(a)

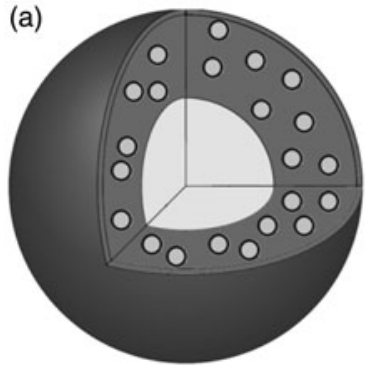

(b)

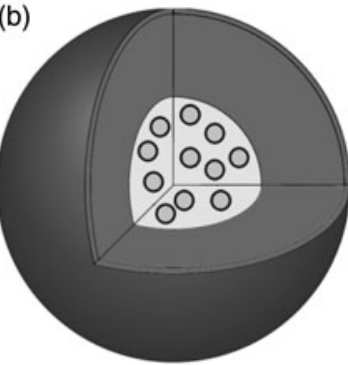

(c)

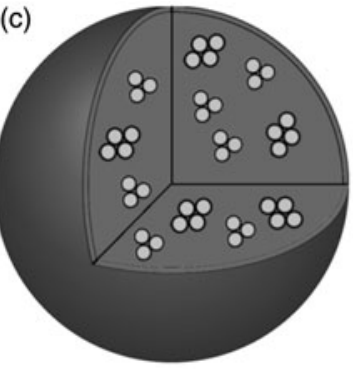

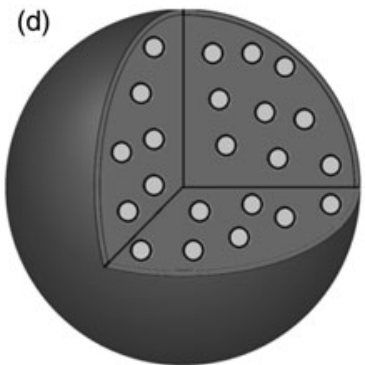

Figure 3. Possible structures of polymeric particles according to the distribution of drug molecules (light grey spheres) in the polymeric matrix (dark grey filling). Capsule structures can contain drug molecules into the shell (light grey filling) (a) or in the core (b). Sphere structures can be constituted by drug aggregates (c) or molecularly dispersed drug (d).

controlling and sustaining the drug release during the particle biodistribution and at the deposition site, altering the whole pharmacokinetic profile of the drug molecule in order to achieve an increased therapeutic efficacy and reduction of side effects. Further, the pattern of release, as well as particle degradation can be readily modulated by the choice of matrix constituents. As liposomes, polymeric particles can target a specific site through attachment of ligands to their surface and this system can be administrated by various routes, including oral, nasal, parenteral, intra-ocular and others (Lehner et al., 2013).

Table 4 shows plenty of experimental studies in which the development of opioid entrapment into polymeric particles has been investigated. Most of the studies have described opioid entrapment in spheres, with an average encapsulation efficiency of $80 \%$.

One of the first works on this matter demonstrated the microencapsulation of tramadol ionically complexed to a sulphonic acid cation-exchange resin. Considering that this complex is unable of establishing a sustainable drug release by itself, the polymer microencapsulation seemed to be an interesting alternative. An ethylcellulose microcapsule wall provided a sustained release of tramadol. The drug release profile was strongly influenced by viscosity of ethylcellulose pre-solution used for spray drying process. Low and middle viscous polymer solution obtained the best results, whereas the high viscosity solution provided coalesced microcapsules with a burst release of drug (Zhang et al., 2000).

In vitro tests also demonstrated a prolonged release of opioids on aqueous media. The use of hydrophobic polymers, such as ethylcellulose, kollidon ${ }^{\circledR}$ SR and PLLA lead to a wide prolonged release of opioid molecules for about $24 \mathrm{~h}$. Considering the use of water-soluble opioids, such as morphine and tramadol, the release can be ruled mainly by polymer swelling, porous diameter on the particle surface or even by polymer degradation rate in the release media (Morales et al., 2004; Arias et al., 2009; Aamir et al., 2011; Chen et al., 2013a). The use of hydrophilic polymers in particle tailoring in general reduces the drug release time due to their solubilisation or hydrolyses upon aqueous media. The use of HPMC in a polymeric blend leads to a total release of tramadol in $12 \mathrm{~h}$ (Patel et al., 2011). Chitosan, a hydrophilic and highly swellable polymer, conferred a total release for up to $5 \mathrm{~h}$ to the microencapsulated tramadol. The use of crosslinkers modulates the particle porosity reducing the drug release (Harris et al., 2010). The addition of a hydrophilic nonhydrolysable monomer, PEG, on PLLA structure accelerated the morphine release by attraction of $\mathrm{H}_{2} \mathrm{O}$ molecules to the particle matrix, acting as 'water pump' favouring the drug dissolution on release media (Chen et al., 2013a).

The production technique is also pivotal for that matter. According to production steps, most opioid molecules can be distributed on the particle surface, leading to a significant burst release in the first minutes of exposure to a release media (Chen et al., 2013a). In addition, the low chemical affinity between the drug and the matrix can favour a phase separation during particle preparation, leading to significant burst release, as demonstrated for morphine-loaded PLLA microparticles in which $50 \%$ of the drug was released on the first $4 \mathrm{~h}$ (Zhang et al., 2012).

Despite the large number of studies of opioid-loaded polymer particles, there is still a lack of in vivo tests performed with these systems, which impairs the interpretation of numerous possible effects of body compartments on the performance of these formulations. In this context, a pharmacokinetic work with thienorphine, a synthetic opioid analogue of buprenorphine produced by Beijing Institute of Pharmacology and Toxicology 


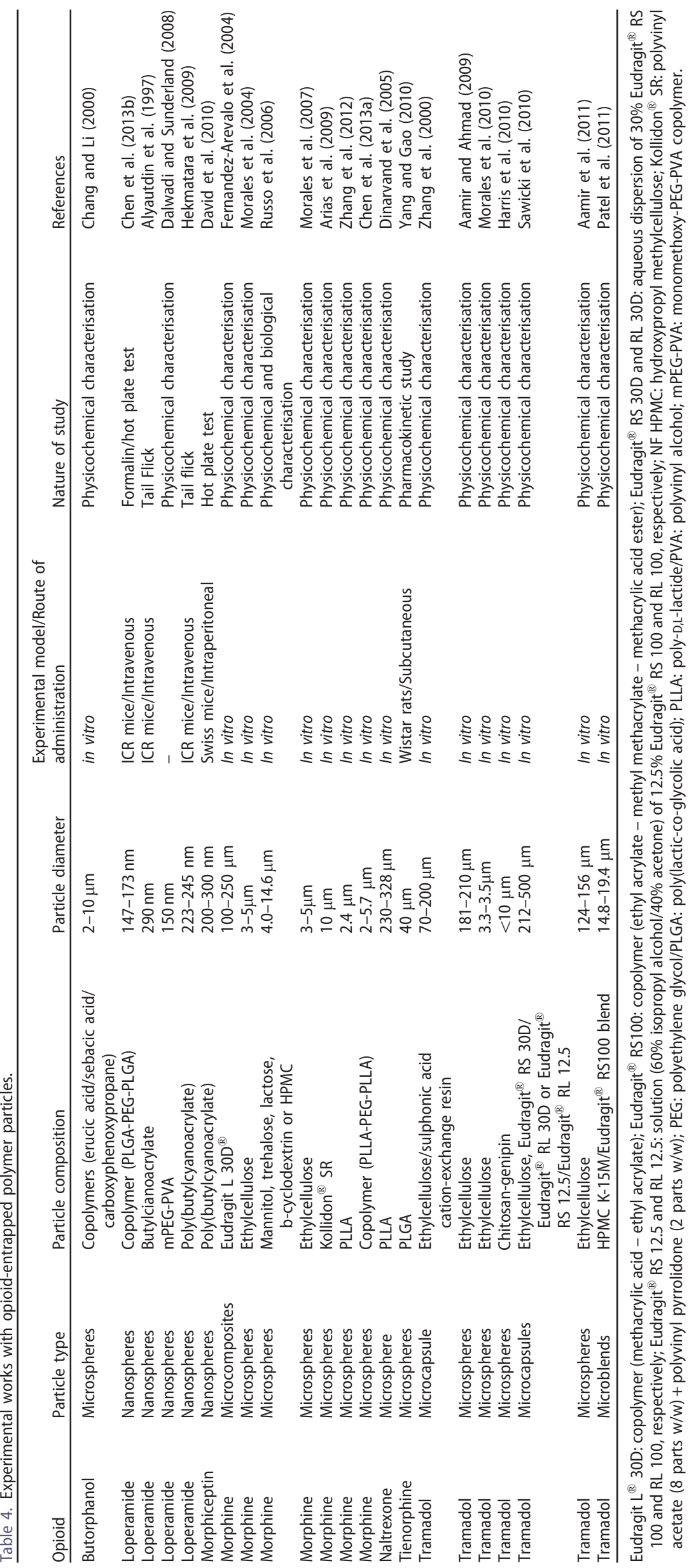


(China), was performed. After a subcutaneous injection of thienorphine-loaded PLGA microspheres, the drug plasma concentration was maintained at a relatively high level $(3-5 \mathrm{ng} / \mathrm{mL})$ for almost 30 days, whereas the free drug formulation had its concentration decreased dramatically just after administration (Yang and Gao, 2010).

The use of nanoparticles can increase the range of applications of drug molecules by improvement of some physical characteristics. Morphiceptin, an opioid agonist peptide, has its analgesia effect upon systemic administration limited by its low diffusion through the blood-brain-barrier (BBB). The morphiceptin encapsulation on poly(butylcyanoacrylate) nanoparticles increased significantly its central analgesia on hot plate model, and increased even more when the particles were coated with polysorbate 80 (David et al., 2010). Similar results were obtained for loperamide, other drug that does not cross the BBB. Loperamide encapsulated into PLGA-PEGPLGA nanoparticles had their antinociceptive activity on formalin test improved after being coated with polysorbate 80 and poloxamer 188 (Chen et al., 2013b). It has been described in the literature that the surfactant coating of nanoparticles attracts the blood stream apolipoproteins after administration. Considering their similarity to lipoproteins, the apolipoproteins mediate via receptor the nanoparticle endocytosis on brain capillary endothelium. Then, the carried drug can be delivered into the brain improving its efficacy (Kreuter et al., 2002; Wohlfart et al., 2012; Grabrucker et al., 2013; Joseph and Saha, 2013).

An interesting alternative for prolonged opioid release system can be the covalent linking of the drug molecule with particle matrix. In this case, the release mechanism is determined by degradation rate of the particle. The literature describes the production of microparticles containing the complex morphine Eudragit ${ }^{\circledR}$ 30D for extended release. More recently, the synthesis of a polymer constituted by morphine molecules chemically incorporated into a poly(anhydride-ester) backbone - polymorphine - was studied. In vivo results from tail flick test with C57/Bl6 mice showed that polymorphine provides analgesia for 3 days, 20 times the analgesic window of free morphine (Rosario-Meléndez et al., 2012).

Even under so many advantageous evidences, it is important to consider the problems associated to polymer carriers. Considering that the control of drug release demands a large amount of encapsulant species, polymeric particles commonly possess a low loading capacity (Martins et al., 2007; Mehnert and Mader, 2001). The high costs for acquisition of most biodegradable polymer particles excipients are also a remarkable drawback of these systems (Joshi and Muller, 2009).

\section{Marketed polymer particle opiates}

\section{Avinza}

Avinza ${ }^{\mathbb{R}}$ contains once-daily extended-release morphine sulphate capsules filled with polymeric beads which provides a sustained release of the drug maintaining therapeutic plasmatic levels up to $24 \mathrm{~h}$. This formulation uses the proprietary Spheroidal Oral Drug Absorption System (SODAS ${ }^{\mathrm{TM}}$ ) technology to produce the extended release of morphine. The SODASTM beads are constituted by ammonium-methacrylate copolymers and after oral administration the gastrointestinal fluids penetrates its polymeric net and solubilises the drug content. The resultant solution then diffuses out in a prolonged manner from the beads leading to a prolonged therapeutic effect (KP, 2008).

Comparative pharmacokinetic studies have demonstrated that Avinza ${ }^{\circledR}$ exhibits less peak-to-trough fluctuations in plasma concentration while providing analgesia statistically identical to that produced by MS Contin ${ }^{\circledR}$ (controlled-release morphine sulphate tablet), Oxycontin ${ }^{\circledR}$ (oxycodone $\mathrm{HCl}$ controlled-release) and six doses of oral morphine sulphate administered every $4 \mathrm{~h}$. Avinza ${ }^{\circledR}$ improves significantly the quality of sleep. However it causes the same side effects of other opioids: constipation, nausea, vomiting, somnolence and mood swings (Caldwell, 2004; Adams et al., 2006; Rauck et al., 2006). Doses of 30-60 mg/day have been shown to be well tolerated by patients with osteoarthritis who have failed other medications (Caldwell, 2004).

\section{Kadian}

The Kadian ${ }^{\circledR}$ extended-release morphine sulphate capsules were firstly approved by FDA in July 1996 for management of moderate to severe pain in cases of a continuous, around-the-clock opioid analgesic is needed for an extended period time. Kadian ${ }^{\circledR}$ capsules are formed by $1.0-1.7 \mathrm{~mm}$ diameter granules which are composed of a globular core particle coated with morphine sulphate additionally covered by a mixed polymeric layer. This coat is constituted by three different polymeric layers, comprising an insoluble matrix at $\mathrm{pH}$ 1-7.5 range, an enteric polymer insoluble at $\mathrm{pH} \mathrm{1-4} \mathrm{and} \mathrm{a} \mathrm{soluble} \mathrm{one} \mathrm{at} \mathrm{pH} 6-7.5$. This mixed coat provides a gradual delivery of morphine sulphate in different sites of gastrointestinal tract (Jitsu, 2000).

$\operatorname{Kadian}^{\circledR}$ pellets are $\mathrm{pH}$-dependent, i.e. the drug release is facilitated in the alkaline environment of intestine, yielding effective plasma morphine concentrations with a relatively small degree of fluctuation for up to $24 \mathrm{~h}$. The bioavailability of Kadian ${ }^{\circledR}$ is not affected by food, so can be administered without regard to meals. The capsules can be administered orally, or can be opened so the pellets contained in the capsules can be sprinkled on apple sauce or administered via gastric feeding tube (Sasaki et al., 2007). The literature has announced that patients with non-adequate management of chronic pain can be successfully switched to $\operatorname{Kadian}^{\circledR}$ (AP, 2010).

Since the gastric environment is too aggressive to the liposomal structure, the only available liposomal opioid in market is designed for parenteral administration. This limitation associated to the risk of particle agglomeration during administration offers a market opportunity for polymer-based products. In this context the two commercially available polymer particulate opioid products grab a significant part of the pharmaceutical market since they have been designed for oral administration. Table 5 summarises a panel of all commercially available particulate opioid formulations. The narrow range of products reveals the lack of investment by pharma industry field on these formulations. It can be linked to the fact that there is still a lack of clinical data proving a significant improvement of opioid therapeutic response and safety profile when associated to these drug delivery systems.

\section{Solid lipid-based particles}

The efforts for discovering alternatives to overcome the limitations of conventional particulate systems resulted on the development of solid lipid nanoparticles, typically named as SLN. First introduced in 1991, SLN are colloidal particles composed by lipids which are solids

Table 5. Commercially available particulate opioid-based products.

\begin{tabular}{lll} 
Products & Opioid & Particle nature \\
\hline Depodur $^{\circledR}$ & Morphine sulphate & Multivesicular liposomes (Depofoam ${ }^{\circledR}$ ) \\
Avinza $^{\circledR}$ & Morphine sulphate & Polymer capsules \\
Kadian $^{\circledR}$ & Morphine sulphate & Polymer capsules \\
\hline
\end{tabular}




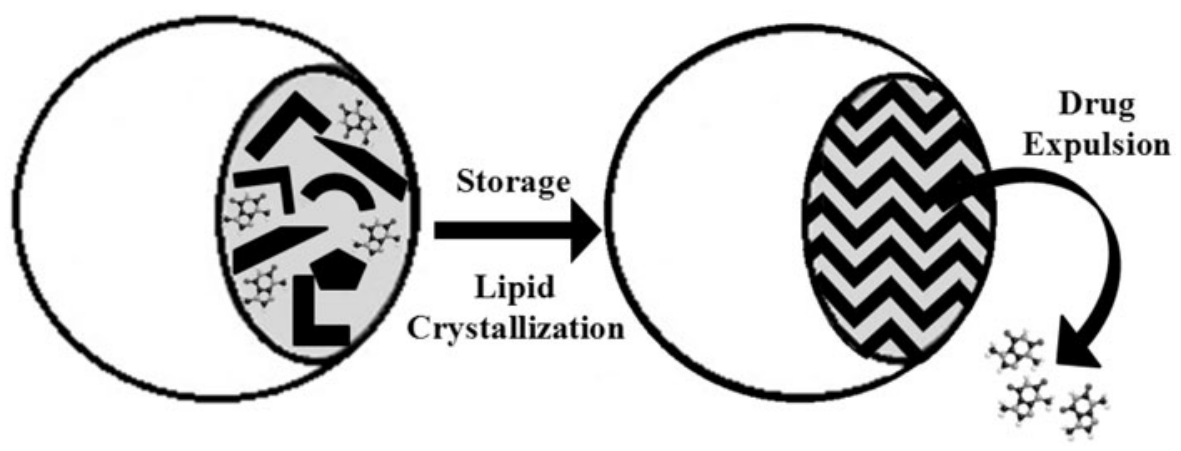

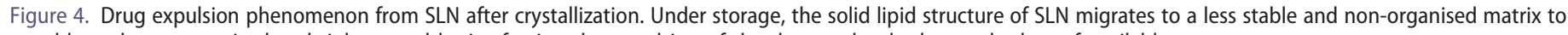
a stable and very organised and tight crystal lattice forcing the expulsion of the drug molecule due to the loss of available space.

at room temperature, including triglycerides, partial glycerides, fatty acids, steroids and waxes (Müller, 1991). The drug incorporated into SLN is released on a prolonged way and the drug concentration can be sustained on blood stream (Müller et al., 2000; Mehnert and Mader, 2001; Kamble et al., 2010). SLN has a broad acceptance owed to the physiological nature of its lipid constituents, preventing acute and chronic toxicity. This is ratified by the Generally Recognised as Safe (GRAS) status conferred by FDA (Mehnert and Mader, 2001; Rahman et al., 2010). In addition, the SLN's solid state favours less complicated sterilisation techniques and higher particle physical stability by avoiding of aggregation, resulting in a larger shelf-life, when compared to liposomal or microemulsion formulations.

Briefly, SLN preparation can be conducted by two main pathways: (i) melting of constitutive lipids and drug solubilisation/ dispersion into molten lipid mass and after some extrusion process the obtained drops are solidified by cooling or (ii) lipid and drugs are dissolved into organic solvent for emulsion preparation in water dispersant media kept under stirring for solvent evaporation and obtainment of solid particles (Sailaja et al., 2011). Concerning these processes, the chemical affinity between the drug molecule and the lipid matrix is highly important to obtain a large payload. Therefore, commonly lipid-soluble drugs show high entrapment ratios, whereas hydrophilic molecules are hardly incorporated into these particles.

Another important issue related to this is the expulsion of the drug molecule from SLN matrix. During storage, the crystalline lipid structures migrate to more stable polymorphic forms, i.e. from $\alpha$-form to $\beta^{\prime}$-form and subsequently to $\beta$-form. In this process, the hydrocarbon chain packing increase enormously with consequent reduction of imperfections in the lipid lattice (Takechi et al., 2007; Da Silva et al., 2009; Souto and Müller, 2010). As depicted in Figure 4, this physical transition of lipids to highly crystalline state into SLN matrix lead to expulsion of mainly hydrophilic drugs (Pietkiewicz et al., 2006). Considering that mixtures of lipids containing fatty acids of different chain length form less perfect crystals with many imperfections, its use on SLN preparation offers more space to accommodate guest molecules, preventing expulsion of drugs.

To overcome this disadvantage, a hybrid lipid particle was created - the nanostructured lipid carriers (NLC). These particles are constituted by a blend of solid and liquid lipids (oils), generating a less organised matrix what facilitates the accommodation of the drug molecule on the particle matrix. Thus, NLC generally present a larger payload ratio than SLN and also no drug expulsion is evidenced during solidifying step of the preparation process, or upon storage (Pardeike et al., 2009; Severino et al., 2012).

The NLC can be classified into three categories according to the structure of their matrix: (i) imperfect type, (ii) multiple types and (iii) amorphous or structureless type. The imperfect type NLC is composed of a minimum amount of liquid lipid with solid saturated and unsaturated lipids of varied chain lengths. In this type, the lipid crystallisation is still an issue, but in tighter rate than that for SLN. The multiple type NLC is composed of a higher concentration of liquid lipids which forms liquid oil nanocompartments in the matrix. Typically the higher oil concentration is associated with faster drug release. The amorphous type NLC is composed by special lipids that remain amorphous upon solid state, such as hydroxyoctacosanylhydroxystearate and isopropyl-myristate. Thus, there is a lack of crystalline structures on the NLC avoiding the drug expulsion (Müller et al., 2002; Puri et al., 2010).

\section{SLN/NLC and opioids}

Table 6 shows the few works concerning the entrapment of opioid molecules into SLN/NLC available in literature. There is no marketed product composed by opioid drugs encapsulated in SLN or NLC.

In order to improve the water solubility of drug molecules, a common strategy is to convert them into salts. Therefore, the opioids are commonly commercialised in salt form. However, considering the general low payload of hydrophilic compounds into SLN, convert opioid salts into their free bases can be an interesting strategy for improving their lipid-solubility, leading to higher entrapment rates. In this context, Küchler et al. (2010) studied the incorporation of morphine free base, converted from morphine hydrochloride, in which $100 \%$ entrapment efficiency into SLN was obtained. On a hot plate test, after intrathecal administration of morphine-loaded SLN to Sprague-Dawley rats, Ji et al. (2008) collected interesting results. They observed an equivalent analgesia efficacy to free morphine formulation, as well as obtained a significant prolongation of analgesia without an increase in the incidence of adverse reactions.

The evaluation of buprenorphine hydrochloride and its methylated prodrugs encapsulated into SLN and NLC demonstrated a higher entrapment rate for the prodrugs, due to their higher lipophilicity. On tail-flick test, after a subcutaneous injection on Sprague-Dawley rats, the buprenorphine-loaded SLN maintained the maximum latency of $12 \mathrm{~s}$ for $8 \mathrm{~h}$, while those for NLC was $4 \mathrm{~h}$ and for aqueous control was $3 \mathrm{~h}$. Among the prodrugs, the buprenorphine-propionate-loaded NLC showed to be the most potent formulation with the maintenance of $100 \%$ antinociception for $10 \mathrm{~h}$. This outcome is related to in vitro drug release data. As the other formulations presented an extremely slow release of the drug/prodrug molecules, it may have led to a under-therapeutic plasma concentrations on experimental models (Wang et al., 2009a, 2009b). 


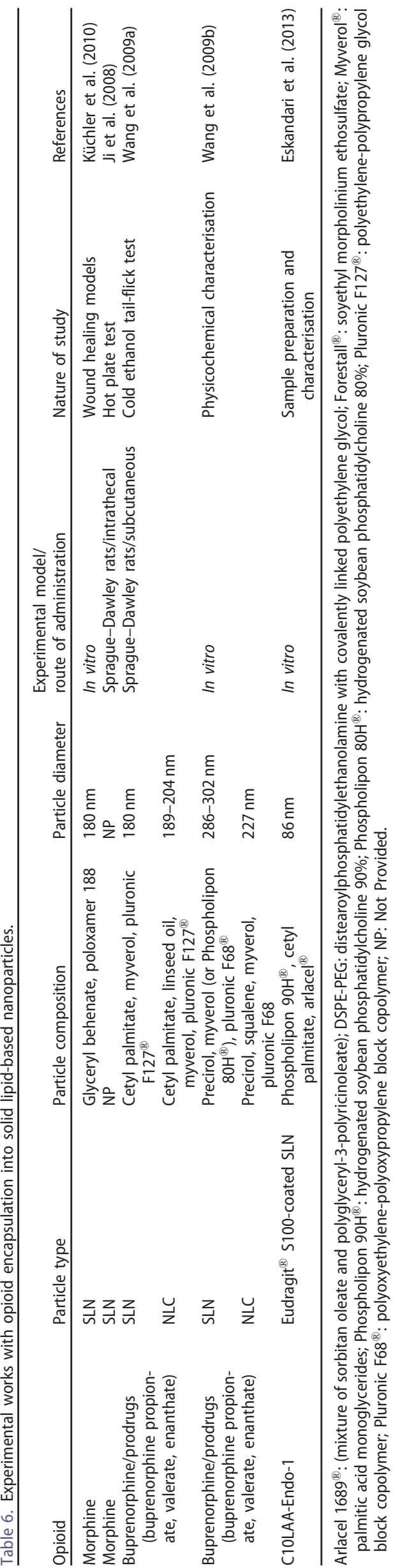

\section{Conclusion}

The comprehension of the importance involved on development of opioid-based controlled release formulations for treatment of chronic pain is already a reality. However, other options on drug delivery must be exploited intending the achievement of more efficient, safer and innovative products. The literature has demonstrated that the association of opioids to particulate systems not only provides a sustained and controlled drug delivery, as well as a superior or equivalent analgesia profile to the free counterparts and reduced side effect occurrence. The maintenance of predictable therapeutic plasma concentration, as well as a reduced drug plasma exposure was crucial for reducing adverse reaction events. The use of various molecules as surface ligands facilitated the interaction of micro and nanoparticles with biomembranes and enhanced opioid absorption, maintaining the prolonged distribution. SLN and NLC seem to be an interesting alternative for future studies, taking into account its large range of advantages and the lack of studies on association with opioids. These studies have not been still enough to warm up the production of new products containing particulate opioids by pharmaceutical industry area. More clinical studies data can help to shift this scenario.

\section{Acknowledgements}

We would like to thank Elsevier Inc. for granting the permission to reuse the Figure 2 of this article (License No. 3782651247197), reprinted from Techniques in Regional Anesthesia and Pain Management, vol. 11, n.1, Nagle PC and Gerancher JC, DepoDur ${ }^{\circledR}$ (extended-release epidural morphine): a review of an old drug in a new vehicle, p.9-18, Copyright $\subset$ (2007).

\section{Declaration of interest}

The authors declare that they have no conflict of interest.

\section{References}

Aamir MN, Ahmad M. Development of tramadol microparticles by non-solvent addition method and their in vitro characterization. Iran Polym J, 2009;18:937-46.

Aamir MN, Ahmad M, Akhtar N, Murtaza G, Khan SA, Nokhodchi A. Development and in vitro-in vivo relationship of controlledrelease microparticles loaded with tramadol hydrochloride. Int J Pharm, 2011;40:738-43.

Adams E, Chwiecko P, Guary J, Ghalie R, De Jong E. (825): Pain control in chronic non-cancer pain patients treated with once-aday AVINZA (morphine sulfate extended-release capsules). J Pain, 2006;7:S57.

Allen TM, Cullis PR. Liposomal drug delivery systems: From concept to clinical applications. Adv Drug Deliv Rev, 2013;65:36-48.

Allouche S, Noble F, Marie N. Opioid receptor desensitization: mechanisms and its link to tolerance. Front Pharmacol, 2014;5:1-20.

Alyautdin RN, Petrov VE, Langer K, Berthold A, Kharkevich DA, Kreuter J. Delivery of loperamide across the blood-brain barrier with polysorbate 80-coated polybutylcyanoacrylate nanoparticles. Pharm Res, 1997;14:325-8.

Anderson JM, Shive MS. Biodegradation and biocompatibility of PLA and PLGA microspheres. Adv Drug Deliv Rev, 2012;64:72-82.

AP. 2010. Product Document Kadian. Bristol, TN: Alpharma Pharmaceuticals, Inc.

Arias JL, Gomez-Gallo A, Delgado AV, Ruiz MA, Kollidon SR. Colloidal particles as vehicles for oral morphine delivery in pain treatment. Colloids Surf B Biointerfaces, 2009;70:207-12. 
Ballantyne JC, Shin NS. Efficacy of opioids for chronic pain: A review of the evidence. Clin J Pain, 2008;24:469-78.

Bernards CM, Luger TJ, Malmberg AB, Hill HF, Yaksh TL. Liposome encapsulation prolongs alfentanil spinal analgesia and alters systemic redistribution in the rat. Anesthesiology, 1992;77:529-35.

Bethune CR, Bernards CM, Bui-Nguyen T, Shen DD, Ho RJ. The role of drug-lipid interactions on the disposition of liposome-formulated opioid analgesics in vitro and in vivo. Anesth Analg, 2001;93: 928-33.

Bourland J. 2011. Opiates history and chemical structures. Drug Testing Matters. Washington, DC: National Laboratory Certified Program.

Breasted JH. 2001. Ancient records of Egypt - The nineteenth dinasty. Champaign (IL): University of Illinois Press.

Budai M, Szabó Z, Szögyi M, Gróf P. Molecular interactions between DPPC and morphine derivatives: A DSC and EPR study. Int J Pharm, 2003;250:239-50.

Buttini F, Colombo P, Rossi A, Sonvico F, Colombo G. Particles and powders: Tools of innovation for non-invasive drug administration. J Control Release, 2012;161:693-702.

Caldwell JR. Avinza - 24-h sustained-release oral morphine therapy. Expert Opin Pharmacother, 2004;5:469-72.

Campbell SB, Hoare T. Externally addressable hydrogel nanocomposites for biomedical applications. Curr Opin Chem Eng, 2014:4:1-10.

Chakravarthi SS, De S, Miller DW, Robinson DH. Comparison of antitumor efficacy of paclitaxel delivered in nano- and microparticles. Int J Pharm, 2010;383:37-44.

Chang HC, Li LC. Sustained-release butorphanol microparticles. Drug Dev Ind Pharm, 2000;26:829-35.

Chen F, Yin G, Liao X, Yang Y, Huang Z, Gu J, Yao Y, Chen X, Gao H. Preparation, characterization and in vitro release properties of morphine-loaded PLLA-PEG-PLLA microparticles via solution enhanced dispersion by supercritical fluids. J Mater Sci Mater Med, 2013a;24:1693-705.

Chen Y-C, Hsieh W-Y, Lee W-F, Zeng D-T. Effects of surface modification of PLGA-PEG-PLGA nanoparticles on loperamide delivery efficiency across the blood-brain barrier. J Biomater Appl, 2013b;27:909-22.

Da Silva E, Bresson S, Rousseau D. Characterization of the three major polymorphic forms and liquid state of tristearin by Raman spectroscopy. Chem Phys Lipids, 2009;157:113-19.

Dalwadi G, Sunderland B. Comparison and validation of drug loading parameters of PEGylated nanoparticles purified by a diafiltration centrifugal device and tangential flow filtration. Drug Dev Ind Pharm, 2008;34:1331-42.

David G, Jaba IM, Tamba B, Bohotin C, Neamtu A. Antinociceptive effect of morphiceptin loaded poly(butyl cyanoacrylate) nanoparticles. Rev Roum Chim, 2010;55:923-31.

Dinarvand R, Moghadam SH, Sheikhi A, Atyabi F. Effect of surfactant HLB and different formulation variables on the properties of poly$D, L$-lactide microspheres of naltrexone prepared by double emulsion technique. J Microencapsul, 2005;22:139-51.

Doth AH, Hansson PT, Jensen MP, Taylor RS. The burden of neuropathic pain: A systematic review and meta-analysis of health utilities. Pain, 2010;149:338-44.

Dumas EO, Pollack GM. Opioid tolerance development: A pharmacokinetic/pharmacodynamic perspective. AAPS J, 2008;10:537-51.

Eskandari S, Varamini P, Toth I. Formulation, characterization and permeability study of nano particles of lipo-endomorphin-1 for oral delivery. J Liposome Res, 2013;23:311-7.

Fang JY, Wu PC, Fang $\mathrm{CL}$, Chen $\mathrm{CH}$. Intravesical delivery of 5-aminolevulinic acid from water-in-oil nano/submicron-emulsion systems. J Pharm Sci, 2010;99:2375-85.
Fernandez-Arevalo M, Alvarez-Fuentes J, Iruin A, Holgado MA. In vitro evaluation of a morphine polymeric complex: Flowability behavior and dissolution study. AAPS PharmSciTech, 2004;5:e39.

Fielding R, Wong W. Prevalence of chronic pain, insomnia, and fatigue in Hong Kong. Hong Kong Med J, 2012;18:S9-12.

Fraser SA, Ting YH, Mallon KS, Wendt AE, Murphy CJ, Nealey PF. Submicron and nanoscale feature depth modulates alignment of stromal fibroblasts and corneal epithelial cells in serum-rich and serum-free media. J Biomed Mater Res A, 2008;86:725-35.

Fröhlich E, Roblegg E. Models for oral uptake of nanoparticles in consumer products. Toxicology, 2012;291:10-7.

Gelperina S, Kisich K, Iseman MD, Heifets L. The potential advantages of nanoparticle drug delivery systems in chemotherapy of tuberculosis. Am J Respir Crit Care Med, 2005;172:1487-90.

Gambling D, Hughes T, Martin G, Horton W, Manvelian G. A comparison of Depodur, a novel, single-dose extended-release epidural morphine, with standard epidural morphine for pain relief after lower abdominal surgery. Anesth Analg, 2005; 100:1065-74.

Gaskin DJ, Richard P. The economic costs of pain in the United States. J Pain, 2012;13:715-24.

Grabrucker A, Chhabra R, Belletti D, Forni F, Vandelli M, Ruozi B, Tosi G. 2013, Nanoparticles as blood-brain barrier permeable CNS targeted drug delivery systems. In: Topics in medicinal chemistry. Berlin/Heidelberg: Springer; pp. 1-19.

Grant GJ, Vermeulen K, Zakowski Ml, Stenner M, Turndorf H, Langerman L. Prolonged analgesia and decreased toxicity with liposomal morphine in a mouse model. Anesth Analg, 1994; 79:706-9.

Gregoriadis G. 2007. Encapsulation of drugs within liposomes by $\mathrm{pH}$ gradient techniques. In: Liposome technology - Entrapment of drugs and other materials into liposomes, 3rd ed. New York: Informa Healthcare, pp. 27-45.

Groenendaal D, Blom-Roosemalen MCM, Danhof M, Lange ECMd. High-performance liquid chromatography of nalbuphine, butorphanol and morphine in blood and brain microdialysate samples: Application to pharmacokinetic/pharmacodynamic studies in rats. J Chromatogr B Analyt Technol Biomed Life Sci, 2005;822:230-7.

Hardy CL, Lemasurier JS, Mohamud R, Yao J, Xiang SD, Rolland JM, O'Hehir RE, Plebanski M. Differential uptake of nanoparticles and microparticles by pulmonary APC subsets induces discrete immunological imprints. J Immunol, 2013;191:5278-90.

Harris R, Lecumberri E, Heras A. Chitosan-genipin microspheres for the controlled release of drugs: Clarithromycin, tramadol and heparin. Mar Drugs, 2010;8:1750-62.

Häuser W, Schmutzer G, Hinz A, Hilbert A, Brähler E. Prävalenz chronischer Schmerzen in Deutschland. Der Schmerz, 2013;27: 46-55.

He S, Zhu J, Xie F. Preparation and characterization of tramadol PEGcoated multivesicular liposomes for sustained release. Pharmazie, 2010;65:467-70.

Van Hecke O, Torrance N, Smith BH. Chronic pain epidemiology and its clinical relevance. Br J Anaesth, 2013;111:13-18.

Hekmatara T, Gelperina S, Vogel V, Yang SR, Kreuter J. Encapsulation of water-insoluble drugs in poly(butyl cyanoacrylate) nanoparticles. J Nanosci Nanotechnol, 2009;9:5091-8.

Hoekman JD, Srivastava P, Ho RJY. Aerosol-stable peptide-coated liposome nanoparticles: A proof-of-concept study with opioid fentanyl in enhancing analgesic effects and reducing plasma drug exposure. J Pharm Sci, 2014;103:2231-9.

Holt D, Viscusi E, Wordell C. Extended-duration agents for perioperative pain management. Curr Pain Headache Rep, 2007; 11:33-7. 
Huber DL. Synthesis, properties, and applications of iron nanoparticles. Small, 2005;1:482-501.

Hung OR, Whynot SC, Varvel JR, Shafer SL, Mezei M. Pharmacokinetics of inhaled liposome-encapsulated fentanyl. Anesthesiology, 1995;83:277-84.

Ji TF, Cao HM, Liang JJ, Wu Q, Miao PL. Effects of intrathecal solid lipid nanoparticles morphine on acute nociception in rats. Chin J Pathophysiol, 2008;24:1993-6.

Jitsu K. Drug information for pain control. KADIAN (morphine sulfate sustained release). Pain Clin, 2000;21:1029-32.

Johannes CB, Le TK, Zhou X, Johnston JA, Dworkin RH. The prevalence of chronic pain in United States adults: Results of an internet-based survey. J Pain, 2010;11:1230-9.

Joseph E, Saha RN. Advances in brain targeted drug delivery: Nanoparticulate systems. PharmaSciTech, 2013;3:1-8.

Joshi MD, Muller RH. Lipid nanoparticles for parenteral delivery of actives. Eur J Pharm Biopharm, 2009;71:161-72.

Kamble VA, Jagdale DM, Kadam VJ. Solid lipid nanoparticles as drug delivery system. Int J Pharma Bio Sci, 2010;1:1-9.

Knych HK, Casbeer HC, Mckemie DS, Arthur RM. Pharmacokinetics and pharmacodynamics of butorphanol following intravenous administration to the horse. J Vet Pharmacol Ther, 2013;36:21-30.

Kohane DS. Microparticles and nanoparticles for drug delivery. Biotechnol Bioeng, 2007;96:203-9.

KP. 2008 Product Document Avinza. Bristol, TN: King Pharmaceuticals, Inc.

Kreuter J, Shamenkov D, Petrov V, Ramge P, Cychutek K, KochBrandt C, Alyautdin R. Apolipoprotein-mediated transport of nanoparticle-bound drugs across the blood-brain barrier. J Drug Target, 2002;10:317-25.

Krugner-Higby L, KuKanich B, Schmidt B, Heath TD, Brown C, Smith LJ. Pharmacokinetics and behavioral effects of an extendedrelease, liposome-encapsulated preparation of oxymorphone in rhesus macaques. J Pharmacol Exp Ther, 2009;330:135-41.

Küchler S, Wolf NB, Heilmann S, Weindl G, Helfmann J, Yahya MM, Stein C, Schafer-Korting M. 3D-wound healing model: Influence of morphine and solid lipid nanoparticles. J Biotechnol, 2010;148: 24-30.

Lasic DD. 1993. Chemistry of Lipids and Liposomes. In: Liposomes, from physics to application. Amsterdam: Elsevier, pp. 9-40.

Lehner R, Wang X, Marsch S, Hunziker P. Intelligent nanomaterials for medicine: Carrier platforms and targeting strategies in the context of clinical application. Nanomedicine, 2013;9:742-57.

Lim GJ, Ishiuji Y, Dawn A, Harrison B, Kim do W, Atala A, Yosipovitch $G$. In vitro and in vivo characterization of a novel liposomal butorphanol formulation for treatment of pruritus. Acta Derm Venereol, 2008;88:327-30.

Maderuelo C, Zarzuelo A, Lanao JM. Critical factors in the release of drugs from sustained release hydrophilic matrices. J Control Release, 2011;154:2-19.

Manchikanti L, Benyamin R, Datta S, Vallejo R, Smith H. Opioids in chronic noncancer pain. Expert Rev Neurother, 2010;10:775-89.

Mantripragada S. 2003. DepoFoam technology. In: Rathbone, MJ, Hadgraft, J, Roberts, MS, eds. Modified-release drug delivery technology. New York: Marcel Dekker, Inc., pp. 705-12.

Martins S, Sarmento B, Ferreira DC, Souto EB. Lipid-based colloidal carriers for peptide and protein delivery - liposomes versus lipid nanoparticles. Int J Nanomedicine, 2007;2:595-607.

Mehnert W, Mader K. Solid lipid nanoparticles: Production, characterization and applications. Adv Drug Deliv Rev, 2001;47:165-96.

Merskey H, Bogduk N. 1994. Classification of chronic pain: descriptions of chronic pain syndromes and definitions of pain terms. Seattle: IASP Press.
Mohanraj V, Chen Y. Nanoparticles - A review. Trop J Pharm Res, 2006;5:561-73.

Morales ME, Gallardo Lara V, Calpena AC, Domenech J, Ruiz MA. Comparative study of morphine diffusion from sustained release polymeric suspensions. J Control Release, 2004;95:75-81.

Morales ME, Ruiz MA, López G, Gallardo V. Development of oral suspensions of microparticles of ethylcellulose with tramadol. Drug Dev Ind Pharm, 2010;36:885-92.

Morales ME, Ruiz MA, Oliva I, Oliva M, Gallardo V. Chemical characterization with XPS of the surface of polymer microparticles loaded with morphine. Int J Pharm, 2007;333:162-6.

Mozafari MR. Liposomes: An overview of manufacturing techniques. Cell Mol Biol Lett, 2005;10:711-9.

Müller RH. 1991. Colloidal carriers for controlled drug delivery and targeting-modification, characterization and in vivo distribution. 1st ed. Boca Raton: Wissenschaftliche Verlagsgesellschaft Stuttgart/CRC Press.

Müller RH, Radtke M, Wissing SA. Solid lipid nanoparticles (SLN) and nanostructured lipid carriers (NLC) in cosmetic and dermatological preparations. Adv Drug Deliv Rev, 2002;54 Suppl 1:S131-55.

Müller RH, Mäder K, Gohla S. Solid lipid nanoparticles (SLN) for controlled drug delivery - A review of the state of the art. Eur J Pharm Biopharm, 2000;50:161-77.

Nagle PC, Gerancher JC. DepoDur ${ }^{\circledR}$ (extended-release epidural morphine): A review of an old drug in a new vehicle. Tech Reg Anesth Pain Manag, 2007;11:9-18.

New RRC. 1990. Introduction. In: Liposomes: A practical approach. New York: Oxford University Press, pp. 1-31.

Ngwuluka NC, Choonara YE, Modi G, du Toit LC, Kumar P, Ndesendo VMK, Pillay V. Design of an interpolyelectrolyte gastroretentive matrix for the site-specific zero-order delivery of levodopa in Parkinson's disease. AAPS PharmSciTech, 2013;14:605-19.

Olivier J-C. Drug transport to brain with targeted nanoparticles. NeuroRx, 2005;2:108-19.

Pardeike J, Hommoss A, Müller RH. Lipid nanoparticles (SLN, NLC) in cosmetic and pharmaceutical dermal products. Int J Pharm, 2009;366:170-84.

Pasero C, McCaffery M. Extended-release epidural morphine (DepoDur). J Perianesth Nurs, 2005;20:345-50.

Patel AS, Soni TG, Thakkar VT, Gandhi TR. Effect of polymeric blend on the dissolution behavior of spray-dried microparticles. Int J Res Pharm Chem, 2011;1:690-701.

Pietkiewicz J, Sznitowska M, Placzek M. The expulsion of lipophilic drugs from the cores of solid lipid microspheres in diluted suspensions and in concentrates. Int J Pharm, 2006;310:64-71.

Pinto Reis C, Neufeld RJ, Ribeiro AJ, Veiga F, Reis PC. Nanoencapsulation I. Methods for preparation of drug-loaded polymeric nanoparticles. Nanomedicine, 2006;2:8-21.

Planas E, Sánchez S, Rodriguez L, Pol O, Puig MM. Antinociceptive/ anti-edema effects of liposomal morphine during acute inflammation of the rat paw. Pharmacology, 2000;60:121-7.

Puri A, Loomis K, Smith B, Lee J, Yavlovich A, Heldman E, Blumenthal R. Lipid-based nanoparticles as pharmaceutical drug carriers: From concepts to clinic. Crit Rev Ther Drug Carrier Syst, 2010;26:1-46.

Rahman Z, Zidan AS, Khan MA. Non-destructive methods of characterization of risperidone solid lipid nanoparticles. Eur J Pharm Biopharm, 2010;76:127-37.

Rauck R, Bookbinder S, Bunker T, Alftine C, Negro-Vilar A,D, Jong E, Gershon S. (820): Once-a-day AVINZA vs. twice daily OxyContin ${ }^{\circledR}$ in an open-label extension (part II) to the ACTION trial for the treatment of chronic moderate-to-severe low back pain. J Pain, 2006;7:S56. 
Reisfield G, Bertholf R, Wilson G. Opiates and opioids: What a difference a name makes. J Opioid Manag, 2007;3:179-80.

Risselada HJ, Marrink SJ. Curvature effects on lipid packing and dynamics in liposomes revealed by coarse grained molecular dynamics simulations. Phys Chem Chem Phys, 2009;11:2056-67.

Rosario-Meléndez R, Harris CL, Delgado-Rivera R, Yu L, Uhrich KE. PolyMorphine: An innovative biodegradable polymer drug for extended pain relief. J Control Release, 2012;162:538-44.

Russo P, Sacchetti C, Pasquali I, Bettini R, Massimo G, Colombo P, Rossi A. Primary microparticles and agglomerates of morphine for nasal insufflation. J Pharm Sci, 2006;95:2553-61.

Sailaja AK, Amareshwar P, Chakravarty P. Formulation of solid lipid nanoparticles and their applications. Curr Pharma Res, 2011;1:197-203.

Sakakibara T, Wang Z, Paholpak P, Kosuwon W, Oo M, Kasai Y. A comparison of chronic pain prevalence in Japan, Thailand, and Myanmar. Pain Physician, 2013;16:603-8.

Sasaki J, Weil AJ, Ross EL, Nicholson BD. Effectiveness of polymercoated extended-release morphine sulfate capsules in older patients with persistent moderate-to-severe pain: A subgroup analysis of a large, open-label, community-based trial. Curr Ther Res Clin Exp, 2007;68:137-50.

Sawicki W, Mazgalski J, Jakubowska I. Hot tabletting of slow-release tramadol hydrochloride microcapsules with cores obtained via compaction . Drug Dev Ind Pharm, 2010;36:209-17.

Schopflocher D, Taenzer P, Jovey R. The prevalence of chronic pain in Canada. Pain Res Manag, 2011;16:445-50.

Severino P, Andreani T, Macedo AS, Fangueiro JF, Santana MH, Silva AM, Souto EB. Current state-of-art and new trends on lipid nanoparticles (SLN and NLC) for oral drug delivery. J Drug Deliv, 2012;2012:750891.

Shaji J, Patole V. Protein and peptide drug delivery: Oral approaches. Indian J Pharm Sci, 2008;70:269-77.

Smith LJ, Krugner-Higby L, Clark M, Wendland A, Heath TD. A single dose of liposome-encapsulated oxymorphone or morphine provides long-term analgesia in an animal model of neuropathic pain. Comp Med, 2003;53:280-7.

Souto EB, Müller RH. 2010. Lipid nanoparticles: Effect on bioavailability and pharmacokinetic changes drug delivery. In: Hofmann FB, ed. Handbook of Experimental Pharmacology, Vol. 197. Berlin: Springer-Verlag, pp. 115-41.

Sugar SL, Jr, LRH, Shannon P, Thomas LC, Nossaman BD. Comparison of extended-release epidural morphine with femoral nerve block to patient-controlled epidural analgesia for postoperative pain control of total knee arthroplasty: A case-controlled study. Ochsner J, 2011;11:17-21.

Takechi C, Kawaguchi T, Kaneko F, Yamamuro O, Akita H, Ono M, Suzuki M. Incoherent quasielastic neutron scattering study on the polymorphism of tristearin: Dynamical properties of hydrocarbon chains. J Phys Chem B, 2007;111:9706-10.
Tracey I, Bushnell MC. How neuroimaging studies have challenged us to rethink: Is chronic pain a disease? J Pain, 2009; 10:1113-20.

Trescot AM, Glaser SE, Hansen H, Benyamin R, Patel S, Manchikanti L. Effectiveness of opioids in the treatment of chronic non-cancer pain. Pain Physician, 2008a;11:S181-200.

Trescot AM, Datta S, Lee M, Hansen H. Opioid pharmacology. Pain Physician, 2008b;11:S133-53.

Van Den Kerkhof EG, Carley ME, Hopman WM, Ross-White A, Harrison MB. Prevalence of chronic pain and related risk factors in military veterans: A systematic review protocol. JBI Database Syst Rev Implement Rep, 2014;12:46-55.

Vanterpool S, Coombs R, Fecho K. Continuous epidural infusion of morphine versus single epidural injection of extendedrelease morphine for postoperative pain control after arthroplasty: A retrospective analysis. Ther Clin Risk Manag, 2010;6: 271-7.

Wang JJ, Liu KS, Sung KC, Tsai CY, Fang JY. Lipid nanoparticles with different oil/fatty ester ratios as carriers of buprenorphine and its prodrugs for injection. Eur J Pharm Sci, 2009a;38:138-46.

Wang J-J, Liu K-S, Sung KC, Tsai C-Y, Fang J-Y. Skin permeation of buprenorphine and its ester prodrugs from lipid nanoparticles: Lipid emulsion, nanostructured lipid carriers and solid lipid nanoparticles. J Microencapsul, 2009b;26:734-47.

Watanabe K, Kaneko M, Maitani Y. Functional coating of liposomes using a folate-polymer conjugate to target folate receptors . Int J Nanomedicine, 2012;7:3679-88.

WHO. 2007. Normative guidelines on pain management - Report of a Delphi Study to determine the need for guidelines and to identify the number and topics of guidelines that should be developed by WHO. Geneva: World Health Organization.

Wohlfart S, Gelperina S, Kreuter J. Transport of drugs across the blood-brain barrier by nanoparticles. J Control Release, 2012;161: 264-73.

Wood LD, Neumiller JJ, Carlson J, Setter SM, Corbett CF. Challenges of medication management in hospitalized patients with Parkinson's disease. . Am J Health Syst Pharm, 2010;67:2059-63.

Yaksh TL, Provencher JC, Rathbun ML, Kohn FR. Pharmacokinetics and efficacy of epidurally delivered sustained-release encapsulated morphine in dogs. Anesthesiology, 1999;90:1402-12.

Yang Y, Gao Y. Preparation and in vivo evaluation of thienorphineloaded PLGA microspheres. Pharmazie, 2010;65:729-32.

Zhang Y-Z, Liao X-M, Yin G-F, Yuan P, Huang Z-B, Gu J-W, Yao Y-D, Chen $X-C$. Preparation of water soluble drugs-loaded microparticles using modified solution enhanced dispersion by supercritical CO2. Powder Technol, 2012;221:343-50.

Zhang Y, Chan HF, Leong KW. Advanced materials and processing for drug delivery: The past and the future. Adv Drug Deliv Rev, 2013;65:104-20.

Zhang ZY, Ping QN, Xiao B. Microencapsulation and characterization of tramadol-resin complexes. J Control Release, 2000;66:107-13. 